\title{
Predicting the restrictive eating, exercise, and weight monitoring compulsions of anorexia nervosa
}

\author{
E. Caitlin Lloyd ${ }^{1} \cdot$ Maria Øverås ${ }^{2} \cdot \varnothing y v i n d ~ R \varnothing^{2,3} \cdot$ Bas Verplanken $^{4} \cdot$ Anne M. Haase ${ }^{1}$
}

Received: 21 January 2018 / Accepted: 13 March 2019 / Published online: 21 March 2019

(c) The Author(s) 2019

\begin{abstract}
Purpose Compulsions surrounding restrictive eating, exercise, and weight monitoring are thought to maintain abnormal eating behaviour in individuals with anorexia nervosa (AN). This study aimed to determine if AN psychopathology and trait anxiety explain the presence of restrictive eating, exercise, and weight monitoring compulsions in a mixed sample.

Methods Participants were 31 females with AN and 31 age and gender-matched healthy individuals (HC). Restrictive eating, exercise and weight monitoring compulsion presence was compared between AN and HC groups. Multivariable poisson regression analyses, adjusted for diagnostic status, were conducted to assess the association of both AN psychopathology and trait anxiety with compulsions across the mixed group.

Results Individuals with AN endorsed a greater number of restrictive eating, exercise and weight monitoring compulsions compared to HC. In adjusted poisson regression analyses neither AN psychopathology nor trait anxiety predicted compulsion presence: incidence rate ratio (IRR) for AN psychopathology $=1.15$ [95\% CI 0.84, 1.57], $p=0.39$; IRR for trait anxiety $=1.01[95 \%$ CI $0.97,1.06], p=0.50$.

Conclusions Greater presence of restrictive eating, exercise and weight monitoring compulsions was reported by individuals with AN, supporting the conceptualisation of disorder behaviours as compulsive. The study was underpowered to robustly evaluate the association between predictors of interest and the compulsions outcome, largely owing to the small sample size. Further investigation is required, ideally using methods able to identify causal and mediation effects.
\end{abstract}

Level of evidence Level V, cross-sectional study.

Keywords Anxiety $\cdot$ Anorexia nervosa $\cdot$ Compulsive behaviour $\cdot$ Compulsions

\section{Introduction}

Anorexia nervosa (AN) has a range of severely detrimental effects on physical wellbeing [1], and the highest mortality rate of any psychiatric condition [2]. These adverse outcomes arise from individuals with AN consistently

E. Caitlin Lloyd

e.caitlin.lloyd@bristol.ac.uk

1 Centre for Exercise, Nutrition and Health Sciences, School of Policy Studies, University of Bristol, Bristol BS8 1TZ, UK

2 Regional Unit for Eating Disorders (RASP), Division of Mental Health and Addiction, Oslo University Hospital, Oslo, Norway

3 Institute of Clinical Medicine, University of Oslo, Oslo, Norway

4 University of Bath, Bath, UK restricting their intake, such that a significantly low weight is maintained [3].

The inadequate calorie intake of individuals with $\mathrm{AN}$ is supported by rituals surrounding restrictive eating, exercise and weight monitoring. At mealtimes individuals with AN tend to eat in very particular ways, for example cutting food into tiny pieces, and completing meals extremely slowly [4]. Engagement in rule-driven and repetitive schedules of exercise [5, 6], and body checking, or stereotyped weight monitoring behaviour [7], is also common to individuals with AN. It is thought that body checking behaviours foster fears and preoccupations with eating and weight-gain, to encourage the continued dietary restriction that is achieved directly by eating and exercise behaviours $[8,9]$.

The rituals surrounding restrictive eating, exercise and weight monitoring are maladaptive for individuals with AN given their need to gain weight. Individuals with AN report having little control over the rituals, and feeling a "need" 
to engage in them, despite often simultaneously expressing desires to recover [10]. As such, the rituals endorsed by individuals with AN are suggested to be compulsive [11], compulsivity defined as a trait promoting the persistent repetition of actions that have adverse outcomes [12]. Further, compulsions are well characterised to possess a strong urgelike quality [13]. Given their role in maintaining the low weight of individuals with AN, it would be useful to address compulsive behaviours surrounding restrictive eating, exercise and weight monitoring in AN treatment. For this to be possible; however, the determinants of compulsions must be identified.

Existing literature suggests that AN psychopathology (drive for thinness/restriction, and eating/weight concern $[3,14])$ and trait anxiety predict engagement in compulsive behaviour surrounding restrictive eating, exercise and weight monitoring. AN psychopathology is associated with more frequent body checking, and compulsive exercise, in clinical and community samples [15-18]. Using a novel measure of compulsive starvation, Godier and Park [19] found this construct to be positively associated with AN psychopathology in a healthy control (HC) and AN group. The severity of rituals surrounding restrictive eating, exercise and weight monitoring, in terms of the interference with daily functioning and distress caused, also increases with greater AN psychopathology [20].

Trait anxiety is positively associated with restrictive eating behaviour [21] and compulsive exercise [22] in AN populations, and with compulsive exercise in community samples [23]. Furthermore, trait anxiety predicts a greater frequency and duration of episodes characterised by high levels of state anxiety [24], and state anxiety is associated with an increased likelihood of engaging in restrictive eating, exercise, and weight monitoring behaviour in individuals with AN [25-27]. The role of anxiety in behaviour typical of AN is particularly important to clarify, given treatment tends to focus on weight-restoration and addressing eating disorder specific cognition, as opposed to more general psychopathology.

The current study aims to confirm the presence of compulsions surrounding restrictive eating, exercise and weight in AN. In addition, the study will evaluate the relationships of AN psychopathology and trait anxiety with compulsive behaviour typical of AN in a clinical and community population, with a view to informing how AN behavior may be maintained. It was hypothesised that greater levels of AN psychopathology, and greater levels of anxiety, would be associated with greater engagement in compulsions typical of $\mathrm{AN}-$ in $\mathrm{AN}$ and $\mathrm{HC}$ groups.

\section{Methods}

\section{Data sources}

Data for the present study was originally collected to investigate memory and perception of body image in AN [28]. The study was completed at the Regional Department for Eating Disorders (RASP), Oslo, Norway, and approved by the Regional Ethical Committee for Medical Research. Informed written consent was obtained from all participants, or from parents of participants when participants were under the age of 16 (the legal age at which consent may be provided in Norway).

\section{Participants}

Fifty females with AN were included in the original study, recruited from 5 specialist eating disorder units in Norway (inpatient and outpatient). Once AN participant recruitment was complete, 35 healthy adolescent/young adult females (HC) from schools and universities local to RASP were recruited. This group was selected on the basis of having a similar age-distribution to the AN sample.

Participants were excluded from the current investigation if they were missing measures of the study variables. Of the originally recruited participants, 13 individuals (11 $\mathrm{AN}$ and $2 \mathrm{HC}$ ) had not completed the measure assessing the presence of eating, exercise and weight monitoring compulsions, and one AN participant was missing trait anxiety information.

The AN group were administered the Eating Disorder Examination, based on the Diagnostic and Statistical Manual of Mental Disorders, fourth edition (DSM-IV [29]), to validate diagnoses. Duration of illness was assessed by way of self-report questionnaire. Height and weight of AN participants was assessed by clinical staff and reported to researchers if participants consented, for calculation of body mass index (BMI). Seven of the recruited AN group were excluded from the current investigation because records indicated that they did not meet any AN criteria $(n=3)$, or did not experience psychopathology that is typical of $\operatorname{AN}(n=4)$. The Norwegian translation of the Eating Disorders Examination self-report, the EDE-Q [30], was used to screen HC for AN psychopathology. Three HC were excluded because their global EDE-Q scores were above four, thus indicating clinically significant AN psychopathology. The EDE-Q is described further in the measures section. Researchers recorded the BMI of HC during the study assessment, following height and weight measurement.

Participants of the current study comprised $31 \mathrm{AN}$, and $31 \mathrm{HC}$, who were aged between 14 and 27. Of the AN 
group, 20 participants met all DSM-IV criteria for AN. Eleven individuals with AN had a bodyweight that was higher than $85 \%$ of that expected, due to weight increases resulting from hospital treatment, and/or did not meet menstruation criteria. These participants were included. Amenorrhea is no longer a criterion for AN [3], and we were interested in the factors underlying engagement in maladaptive behaviour that can persist following weightgain. There were no significant differences in trait anxiety, AN psychopathology, and endorsement of eating, exercise and weight-related compulsions, between individuals meeting full versus partial criteria for AN.

\section{Measures}

\section{Explanatory variables}

Trait anxiety was measured by the trait anxiety subscale of the State-Trait Anxiety Inventory (STAI; [31]). AN psychopathology was indexed by global score on the Norwegian translation of the EDE-Q [30]. The EDE-Q assesses AN psychopathology: desire for thinness and weight-loss; fears surrounding eating and weight-gain; and dissatisfaction and preoccupation with weight, shape and eating. The global score is the average of four subscales: restraint; weight concern; shape concern; and eating concern. Both the EDE-Q and STAI are well established to have excellent psychometric properties and are commonly used to assess the constructs of interest [32-37]. The Norwegian translation of the EDE-Q has demonstrated satisfactory psychometric properties [38].

\section{Outcome variable}

The presence of eating, exercise and weight monitoringrelated compulsions was assessed by the compulsions severity subscale of the Child Obsessive Compulsive Inventory (ChOCI; [39]). In particular, we were interested in responses to the question that asks participants to name their 3 most severe, or upsetting, compulsions. Responses to this question indicated the extent to which participants experience severe compulsions related to eating, exercise or weight monitoring. Participants are guided that a compulsion is something they feel they 'have to do and cannot stop' to ensure relevant behaviours are reported. The ChOCI is reported to reliably and validly measure obsessive and compulsive symptom severity in adolescents [39], and so was deemed appropriate for use in a mid-adolescent/early adulthood sample.

An independent rater determined whether named compulsions were related to restrictive eating, exercise or weight monitoring. The number of such compulsions was recorded, to comprise the count variable 'restrictive eating, exercise and weight monitoring compulsions', which had possible values of 0 to 3 . The presence of restrictive eating, exercise and weight monitoring compulsions is a marker of abnormal behaviour, as opposed to cognition, surrounding eating, exercise, and weight.

\section{Data preparation and analysis}

All analyses were conducted using the statistics program Stata [40]. Mean AN psychopathology and trait anxiety, of $\mathrm{AN}$ and HC, was compared using $t$ tests. The number of restrictive eating, exercise and weight monitoring compulsions of AN and HC groups was compared using a Chisquare test. The correlation between AN psychopathology and trait anxiety, both unadjusted and adjusted for diagnostic status, was calculated.

Univariable (single predictor) poisson regression models estimated the association of the predictors AN psychopathology and trait anxiety with the compulsions count variable. A multivariable poisson regression model, adjusted for diagnostic status (i.e., AN versus $\mathrm{HC}$ ), assessed the independent association of each predictor variable with the compulsions outcome. Model coefficients indicate the increased log of expected compulsions count per one unit increase in the predictor. The coefficients were exponentiated to produce incidence rate ratios, indicating the increase in expected compulsions count per one unit increase in the given predictor.

Exploratory analyses assessed whether there was a difference between $\mathrm{AN}$ and $\mathrm{HC}$ groups in the association of predictors (trait anxiety and eating disorder psychopathology) with restrictive eating, exercise and weight monitoring compulsions. This was achieved by adding relevant interaction terms to the poisson regression model. The sample size was such that interaction effect coefficients could not be estimated with confidence, and outcomes of this analysis are not reported; further details are available upon request.

\section{Results}

\section{Sample characteristics}

Table 1 details the demographic and clinical characteristics of the sample. AN psychopathology was much higher in AN as compared to HC (Cohen's $d$ for between group differences $=3.00$ ), as was trait anxiety (Cohen's $d$ for between group differences $=3.22$ ). Individuals with $\mathrm{AN}$ also reported a greater number of compulsions compared to $\mathrm{HC}$.

\section{Preliminary analyses}

AN psychopathology and trait anxiety were correlated $(R=0.82, p<0.001)$. This association remained but was 
much weaker when adjusting for diagnostic status $(R=0.20$, $p=0.12)$. Greater AN psychopathology and trait anxiety were associated with an increased rate of eating, exercise and weight monitoring compulsions in univariable models (Table 2).

\section{Main analyses}

The multivariable regression model accounted for $21.0 \%$ of the variance in the count of restrictive eating, exercise and weight monitoring compulsions; $\chi^{2}(3)=32.18$, $p \leq 0.001$. There was no strong evidence to support any of the predictors explaining unique variance in the compulsions outcome. Table 3 provides further information.

\section{Discussion}

This study found that individuals with AN endorsed a greater number of restrictive eating, exercise and weight monitoring compulsions compared to $\mathrm{HC}$, supporting behaviours typical of AN being conceptualised as compulsive [4]. The compulsive nature of disorder behaviours likely promotes the persistence of $\mathrm{AN}$, and thus it is important to understand

Table 1 Participant characteristics

\begin{tabular}{|c|c|c|c|}
\hline & $\begin{array}{l}\text { Women with } \mathrm{AN}(N=31) \\
M(\mathrm{SD})\end{array}$ & $\begin{array}{l}\text { Healthy women }(N=31) \\
M(\mathrm{SD})\end{array}$ & $T$ statistic $(p)$ \\
\hline $\mathrm{Age}^{\mathrm{a}}$ & $19.6(3.27)$ & $18.6(3.71)$ & $1.10(0.28)$ \\
\hline $\operatorname{BMI}\left(\mathrm{kg} / \mathrm{m}^{2}\right)^{\mathrm{b}}$ & $16.33(2.13)$ & $21.78(2.73)$ & $8.58(<0.001)$ \\
\hline Duration of illness (months) & $32(27.55)$ & & \\
\hline AN psychopathology & $3.62(1.09)$ & $0.81(0.75)$ & $11.87(<0.001)$ \\
\hline \multirow[t]{2}{*}{ Trait anxiety } & $62.81(7.23)$ & $37.10(8.68)$ & $12.68(<0.001)$ \\
\hline & Count $(N)$ & Count $(N)$ & $\chi^{2}$ statistic $(p)$ \\
\hline \multicolumn{4}{|c|}{ Number of eating, exercise and weight monitoring compulsions } \\
\hline 0 & 8 & 26 & $22.60(<0.001)$ \\
\hline 1 & 10 & 4 & \\
\hline 2 & 7 & 1 & \\
\hline 3 & 6 & 0 & \\
\hline
\end{tabular}

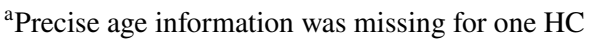

${ }^{\mathrm{b}} \mathrm{BMI}$ data for one AN participant, and two $\mathrm{HC}$, was missing

Table 2 Univariable poisson regression models for the prediction of restrictive eating, exercise and weight monitoring compulsions by trait anxiety and AN psychopathology

\begin{tabular}{|c|c|c|c|c|c|c|c|}
\hline \multicolumn{2}{|c|}{ Univariable regression of compulsions } & \multicolumn{4}{|c|}{ Coefficient estimates } & \multicolumn{2}{|c|}{ Model statistics } \\
\hline \multicolumn{2}{|c|}{ Explanatory variable } & $B$ & SE & Incident rate ratio $[95 \% \mathrm{CI}]$ & $p$ value & $\overline{\chi^{2}(d f)}$ & Pseudo $R^{2}$ \\
\hline \multirow[t]{2}{*}{ Model 1} & AN psychopathology & 0.46 & 0.10 & $1.59[1.31,1.93]$ & $<0.001$ & \multirow{2}{*}{$\begin{array}{l}25.96(1) \\
p<0.001\end{array}$} & \multirow[t]{2}{*}{0.17} \\
\hline & Constant & -1.57 & 0.37 & $0.21[0.10,0.42]$ & $<0.001$ & & \\
\hline \multirow[t]{2}{*}{ Model 2} & Trait anxiety & 0.06 & 0.01 & $1.06[1.03,1.08]$ & $<0.001$ & \multirow{2}{*}{$\begin{array}{l}26.52(1) \\
p<0.001\end{array}$} & \multirow[t]{2}{*}{0.17} \\
\hline & Constant & -3.35 & 0.74 & $0.03[0.01,0.15]$ & $<0.001$ & & \\
\hline
\end{tabular}

Table 3 Adjusted Multivariable poisson regression model for the prediction of restrictive eating, exercise and weight monitoring compulsions by AN psychopathology and trait anxiety

\begin{tabular}{lrllllll}
\hline $\begin{array}{l}\text { Multivariable regres- } \\
\text { sion of compulsions }\end{array}$ & \multicolumn{3}{l}{ Coefficient estimates } & & \multicolumn{2}{l}{ Model statistics } \\
\cline { 2 - 5 } Explanatory variable & $B$ & SE & Incident rate ratio [95\% CI $]$ & $P$ value & & $\chi^{2}(d f)$ & Pseudo $R^{2}$ \\
\hline Diagnostic status (AN) & 1.19 & 0.73 & $3.30[0.80,13.68]$ & 0.10 & $32.18(3)$ & 0.21 \\
AN psychopathology & 0.14 & 0.16 & $1.15[0.84,1.57]$ & 0.39 & $p \leq 0.001$ & \\
Trait anxiety & 0.01 & 0.02 & $1.01[0.97,1.06]$ & 0.50 & & \\
Constant & -2.30 & 0.88 & $0.10[0.02,0.56]$ & $<0.01$ & & \\
\hline
\end{tabular}


the determinants of disorder-relevant compulsions in order to develop effective treatment interventions.

The present study particularly sought to understand whether AN psychopathology and trait anxiety predicted compulsive behaviours centred on restrictive eating, exercise and weight monitoring, in individuals with AN and HC. In univariable models, greater AN psychopathology and greater trait anxiety predicted an increased number of AN compulsions. The direction of association was consistent in multivariable models adjusted for diagnostic status, however, the strength of association was reduced and point estimates less precise (for both trait anxiety and AN psychopathology). Neither AN psychopathology nor trait anxiety was able to explain unique variation in compulsion presence beyond that accounted for by diagnostic status. This contrasts with findings of other studies. Previously relationships between AN psychopathology/anxiety and compulsive behaviour surrounding restrictive eating, exercise and weight monitoring have been reported in populations of either AN or HC individuals [19, 20, 23, 41-43]. One plausible cause of the discrepancy is low power in the current study, mainly owing to a relatively small number of participants-a limitation of the present investigation.

The nature of the compulsions outcome variable will also have limited sensitivity to detect an association between this and AN psychopathology/trait anxiety. Assessment of the number of severe compulsions surrounding restrictive eating, exercise and weight monitoring allowed for the capture of different compulsive behaviours typical of AN. This approach promoted validity in the assessment of whether compulsions were present. However, the range of possible responses was limited. Most individuals with AN reported a non-zero number of compulsions, while most $\mathrm{HC}$ reported no compulsions, meaning variability in the response was particularly low within diagnostic status categories - which, like sample size, has implications for statistical power. Individual differences would be captured to a finer degree by alternative measures of compulsivity. Future studies might use multi-item scales that separately assess compulsive starvation, compulsive exercise and body checking. Alternatively, studies might investigate the presence and severity of a variety of specific restrictive eating, exercise and weight monitoring compulsions characteristic of AN using the Yale-Brown-Cornell Eating Disorder Scale [44].

The study has some important strengths, such as the use of strict inclusion criteria to ensure the AN sample was typical of this population, and appropriate modelling of the count outcome variable within poisson regression models. However, given the discussed methodological shortcomings relating to outcome measurement and sample size, we encourage further investigation into predictors of restrictive eating, exercise and weight monitoring compulsions-in $\mathrm{AN}$ and HC. In addition to AN psychopathology and trait anxiety, other potentially relevant factors (e.g., cognitive processing style, psychiatric comorbidity) may be studied for their association with compulsive behaviour typical of AN. Ideally studies would be adequately powered to explore interaction effects, to understand how predictors of compulsive behaviour may differ between AN and HC. To gain further insight, it would be useful to compare AN subtypes for severity of various illness-related compulsions, as well as for predictors of these compulsions. Future studies might also examine the mechanisms by which determinants are associated with compulsive behaviour surrounding restrictive eating, exercise and weight monitoring, to identify factors that might most usefully be targeted in AN treatment. For example, in this study anxiety and AN psychopathology were related, consistent with findings from studies in clinical [45, 46] and subclinical [47] populations. Should, as has been proposed (e.g., [48-50]), anxiety exert a causal influence on AN psychopathology, and should AN psychopathology in turn cause compulsive behaviour typical of AN, it might be advantageous to address general anxiety (i.e., not that specific to eating and weight-gain) for reduction of both cognitive and behavioural symptoms of AN. Cross-sectional studies such as the present one cannot make inferences regarding the direction of observed associations. For rigorous tests of causal and mechanistic hypotheses longitudinal and experimental designs should be implemented.

\section{Conclusion}

Our findings support AN being characterised as a compulsive disorder, highlighting the importance of identifying determinants of compulsive behaviour surrounding restrictive eating, exercise and weight monitoring to inform AN treatment. The study did not find strong evidence to support trait anxiety or AN psychopathology being associated with greater engagement in compulsive behaviour typical of AN, in a clinical or community population. The direction of the associations that were observed was, however, consistent with findings of previous studies that do support such relationships to exist. The present investigation was underpowered to assess associations robustly, and further investigation is encouraged-particularly using designs able to establish causality and elucidate mechanisms underpinning causal effects.

Acknowledgements The authors would like to acknowledge the support of Kristin Stedal, $\mathrm{PhD}$, in the completion of this study.

Funding The study was supported by an Economic and Social Research Council (ESRC) Standard Research Studentship award [ES/ J50015X/1] to the first author. 


\section{Compliance with ethical standards}

Conflict of interest On behalf of all authors, the corresponding author states that there is no conflict of interest.

Ethical approval All procedures performed in studies involving human participants were in accordance with the ethical standards of the institutional and/or national research committee and with the 1964 Helsinki declaration and its later amendments or comparable ethical standards. This article does not contain any studies with animals performed by any of the authors.

Informed consent Informed consent was obtained from all individual participants included in the study, and from parents when participants themselves could not legally consent due to being under 16 years of age.

Open Access This article is distributed under the terms of the Creative Commons Attribution 4.0 International License (http://creativeco mmons.org/licenses/by/4.0/), which permits unrestricted use, distribution, and reproduction in any medium, provided you give appropriate credit to the original author(s) and the source, provide a link to the Creative Commons license, and indicate if changes were made.

\section{References}

1. Mehler P, Brown C (2015) Anorexia nervosa-medical complications. J Eat Disord 3:11. https://doi.org/10.1186/s4033 7-015-0040-8

2. Steinhausen H-C (2002) The outcome of anorexia nervosa in the 20th century. Am J Psychiatry 159:1284-1293. https://doi. org/10.1176/appi.ajp.159.8.1284

3. American Psychiatric Association (2013) Diagnostic and statistical manual of mental disorders (DSM- $\left.5^{\circledR}\right)$, 5th edn. American Psychiatric Publishing, Arlington, VA

4. Gianini L, Liu Y, Wang Y, Attia E, Walsh BT, Steinglass J (2015) Abnormal eating behavior in video-recorded meals in anorexia nervosa. Eat Behav 19:28-32. https://doi.org/10.1016/j.eatbe h.2015.06.005

5. Fietz M, Touyz S, Hay P (2014) A risk profile of compulsive exercise in adolescents with an eating disorder: a systematic review. Adv Eat Disord Theory Res Pract 2:241-263. https://doi. org/10.1080/21662630.2014.894470

6. Young S, Touyz S, Meyer C, Arcelus J, Rhodes P, Madden S et al (2017) Validity of exercise measures in adults with anorexia nervosa: the EDE, compulsive exercise test and other self-report scales. Int J Eat Disord 50(5):533-541. https://doi.org/10.1002/ eat.22633

7. Kraus N, Lindenberg J, Zeeck A, Kosfelder J, Vocks S (2015) Immediate effects of body checking behaviour on negative and positive emotions in women with eating disorders: an ecological momentary assessment approach. Eur Eat Disord Rev 23(5):399_ 407. https://doi.org/10.1002/erv.2380

8. Bailey N, Waller G (2017) Body checking in non-clinical women: Experimental evidence of a specific impact on fear of uncontrollable weight gain. Int J Eat Disord 50(6):693-697. https://doi. org/10.1002/eat.22676

9. Calugi S, El Ghoch M, Dalle Grave R (2017) Body checking behaviors in anorexia nervosa. Int J Eat Disord 50(4):437-441. https://doi.org/10.1002/eat.22677

10. Godier LR, Park RJ (2015) Does compulsive behavior in Anorexia Nervosa resemble an addiction? A qualitative investigation. Front Psychol 6:1608. https://doi.org/10.3389/fpsyg.2015.01608
11. Godier LR, Park RJ (2014) Compulsivity in anorexia nervosa: a transdiagnostic concept. Front Psychol 5:778. https://doi. org/10.3389/fpsyg.2014.00778

12. Robbins TW, Gillan CM, Smith DG, de Wit S, Ersche KD (2012) Neurocognitive endophenotypes of impulsivity and compulsivity: towards dimensional psychiatry. Trends Cogn Sci 16(1):81-91. https://doi.org/10.1016/j.tics.2011.11.009

13. Gillan CM, Robbins TW (2014) Goal-directed learning and obsessive-compulsive disorder. Phil Trans R Soc B 369(1655):20130475. https://doi.org/10.1098/rstb.2013.0475

14. Cooper Z, Fairburn C (1987) The eating disorder examination: a semi-structured interview for the assessment of the specific psychopathology of eating disorders. Int J Eat Disord 6(1):1-8. https ://doi.org/10.1002/1098-108X(198701)6:1\%3C1::AID-EAT22 60060102\%3E3.0.CO;2-9

15. Homan K (2010) Athletic-ideal and thin-ideal internalization as prospective predictors of body dissatisfaction, dieting, and compulsive exercise. Body Image 7(3):240-245. https://doi. org/10.1016/j.bodyim.2010.02.004

16. Lavender JM, Wonderlich SA, Crosby RD, Engel SG, Mitchell JE, Crow $S$ et al (2013) A naturalistic examination of body checking and dietary restriction in women with anorexia nervosa. Behav Res Ther 51(8):507-511. https://doi.org/10.1016/j. brat.2013.05.004

17. Stefano EC, Hudson DL, Whisenhunt BL, Buchanan EM, Latner JD (2016) Examination of body checking, body image dissatisfaction, and negative affect using Ecological momentary assessment. Eat Behav 22:51-54. https://doi.org/10.1016/j.eatbeh.2016.03.026

18. Noetel M, Miskovic-Wheatley J, Crosby RD, Hay P, Madden S, Touyz S (2016) A clinical profile of compulsive exercise in adolescent inpatients with anorexia nervosa. J Eat Disord 4:1. https ://doi.org/10.1186/s40337-016-0090-6

19. Godier LR, Park RJ (2015) A novel measure of compulsive food restriction in anorexia nervosa: validation of the self-starvation scale (SS). Eat Behav 17:10-13. https://doi.org/10.1016/j.eatbe h.2014.12.004

20. Jordan J, Joyce PR, Carter FA, McIntosh VV, Luty SE, McKenzie JM et al (2009) The Yale-Brown-Cornell eating disorder scale in women with anorexia nervosa: what is it measuring? Int J Eat Disord 42(3):267-274. https://doi.org/10.1002/eat.20605

21. Steinglass JE, Sysko R, Mayer L, Berner LA, Schebendach J, Wang YJ et al (2010) Pre-meal anxiety and food intake in anorexia nervosa. Appetite 55(2):214-218. https://doi.org/10.1016/j.appet .2010 .05 .090

22. Peñas-Lledó E, Vaz Leal FJ, Waller G (2002) Excessive exercise in anorexia nervosa and bulimia nervosa: relation to eating characteristics and general psychopathology. Int J Eat Disord 31(4):370-375. https://doi.org/10.1002/eat.10042

23. Weinstein A, Maayan G, Weinstein Y (2015) A study on the relationship between compulsive exercise, depression and anxiety. J Behav Addict 4(4):315-318. https://doi. org/10.1556/2006.4.2015.034

24. Edmondson D, Shaffer JA, Chaplin WF, Burg MM, Stone AA, Schwartz JE (2013) Trait anxiety and trait anger measured by ecological momentary assessment and their correspondence with traditional trait questionnaires. J Res Pers. 47(6):843-852. https ://doi.org/10.1016/j.jrp.2013.08.005

25. Engel SG, Wonderlich SA, Crosby RD, Wright TL, Mitchell JE, Crow SJ et al (2005) A study of patients with anorexia nervosa using ecologic momentary assessment. Int J Eat Disord 38(4):335-339. https://doi.org/10.1002/eat.20184

26. Lavender JM, De Young KP, Wonderlich SA, Crosby RD, Engel SG, Mitchell JE et al (2013) Daily patterns of anxiety in anorexia nervosa: associations with eating disorder behaviors in the natural environment. J Abnorm Psychol 122(3):672-683. https://doi. org/10.1037/a0031823 
27. Meyer C, Taranis L, Goodwin H, Haycraft E (2011) Compulsive exercise and eating disorders. Eur Eat Disord Rev 19(3):174-189. https://doi.org/10.1002/erv.1122

28. Øverås M, Kapstad H, Brunborg C, Landrø NI, Lask B (2014) Memory versus perception of body size in patients with anorexia nervosa and healthy controls. Eur Eat Disord Rev 22(2):109-115. https://doi.org/10.1002/erv.2276

29. American Psychiatric Association (2000) Diagnostic and statistical manual of mental disorders (DSM-IV-TR). American Psychiatric Association, Washington, DC

30. Fairburn CG, Beglin SJ (1994) Assessment of eating disorders: Interview or self-report questionnaire? Int J Eat Disord 16(4):363370. https://doi.org/10.1002/1098-108X(199412)16:4\%3C363 ::AID-EAT2260160405\%3E3.0.CO;2-\%23

31. Spielberger CD, Gorsuch RL, Lushene RE (1970) Manual for the state-trait anxiety inventory. Consulting Psychologists Press, Palo Alto, CA

32. Berg KC, Peterson CB, Frazier P, Crow SJ (2012) Psychometric evaluation of the eating disorder examination and eating disorder examination-questionnaire: a systematic review of the literature. Int J Eat Disord 45(3):428-438. https://doi.org/10.1002/eat.20931

33. McDowell I (2006) Measuring health: a guide to rating scales and questionnaires. Oxford University Press, Oxford

34. Mond JM, Hay PJ, Rodgers B, Owen C (2006) Eating Disorder Examination Questionnaire (EDE-Q): norms for young adult women. Behav Res Ther 44(1):53-62. https://doi.org/10.1016/j. brat.2004.12.003

35. Nixon GF, Steffeck JC (1977) Reliability of the state-trait anxiety inventory. Psychol Rep 40(2):357-358. https://doi.org/10.1016/j. brat.2004.12.003

36. Spielberger CD, Gorsuch RL, Lushene R, Vagg PR, Jacobs GA (1983) Manual for the state-trait anxiety inventory. Consulting Psychologists Press, Palo Alto, CA

37. Vigneau F, Cormier S (2008) The factor structure of the StateTrait Anxiety Inventory: an alternative view. J Pers Assess 90(3):280-285. https://doi.org/10.1080/00223890701885027

38. Rø Ø, Reas DL, Lask B (2010) Norms for the Eating Disorder Examination Questionnaire among female university students in Norway. Nord J Psychiatry 64(6):428-432. https://doi. org/10.3109/08039481003797235

39. Shafran R, Frampton I, Heyman I, Reynolds M, Teachman B, Rachman S (2003) The preliminary development of a new selfreport measure for OCD in young people. J Adolesc 26(1):137142. https://doi.org/10.1016/S0140-1971(02)00083-0

40. StataCorp (2015) Stata statistical software, 14 edn. StataCorp LP, College Station
41. Haase AM, Mountford V, Waller G (2011) Associations between body checking and disordered eating behaviors in nonclinical women. Int J Eat Disord 44(5):465-468. https://doi.org/10.1002/ eat. 20837

42. Tasca GA, Balfour L (2014) Attachment and eating disorders: a review of current research. Int J Eat Disord 47(7):710-717. https ://doi.org/10.1002/eat.22302

43. Tasca GA, Illing V, Balfour L, Krysanski V, Demidenko N, Nowakowski J et al (2009) Psychometric properties of self-monitoring of eating disorder urges among treatment seeking women: Ecological momentary assessment using a daily diary method. Eat Behav 10(1):59-61. https://doi.org/10.1016/j.eatbeh.2008.10.004

44. Mazure CM, Halmi KA, Sunday SR, Romano SJ, Einhorn AM (1994) The Yale-Brown-Cornell eating disorder scale: development, use, reliability and validity. J Psychiatr Res 28(5):425-445. https://doi.org/10.1016/0022-3956(94)90002-7

45. Spindler A, Milos G (2007) Links between eating disorder symptom severity and psychiatric comorbidity. Eat Behav 8(3):364 373. https://doi.org/10.1016/j.paid.2012.08.036

46. Sternheim L, Startup H, Schmidt U (2015) Anxiety-related processes in anorexia nervosa and their relation to eating disorder pathology, depression and anxiety. Adv Eat Disord 3(1):13-19. https://doi.org/10.1080/21662630.2014.948469

47. Davis KR, Fischer S (2013) The influence of trait anger, trait anxiety and negative urgency on disordered eating. Pers Individ Differ 54(2):307-310. https://doi.org/10.1016/j.paid.2012.08.036

48. Kaye WH, Fudge JL, Paulus M (2009) New insights into symptoms and neurocircuit function of anorexia nervosa. Nat Rev Neurosci 10(8):573-584. https://doi.org/10.1038/nrn2682

49. Lloyd EC, Frampton I, Verplanken B, Haase AM. How extreme dieting becomes compulsive: a novel hypothesis for the role of anxiety in the development and maintenance of anorexia nervosa. Med Hypotheses. 2017;108(Supplement C):144-150. https://doi. org/10.1016/j.mehy.2017.09.001

50. Nunn K, Frampton I, Lask B (2012) Anorexia nervosa—a noradrenergic dysregulation hypothesis. Med Hypotheses 78(5):580584. https://doi.org/10.1016/j.mehy.2012.01.033

Publisher's Note Springer Nature remains neutral with regard to jurisdictional claims in published maps and institutional affiliations. 